\title{
Industry 5.0 for Sustainable Reliability Centered Maintenance
}

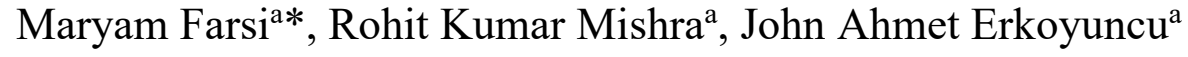 \\ ${ }^{a}$ School of Aerospace, Transport and Manufacturing, Cranfield University, Cranfield MK43 0AL, UK \\ * Corresponding author. Tel.: +44-123-475-0111. E-mail address: maryam.farsi@cranfield.ac.uk
}

\begin{abstract}
Industry 5.0 is based on the idea of merging sustainable development goals and digitalization provisions from the fourth industrial revolution through human-centric solutions, bio-inspired technologies, and cyber safe data transmission. Industries are yet the most significant drivers of the integrated sustainability development (economic, environmental, and social) over the design, manufacturing, operation and disposal of products and services. This research investigates Industry 5.0 indicators that are required to achieve sustainable reliability centered maintenance (RCM) for high-value equipment. The research work examines the feasibility of a correlation between sustainable indicators between operation and maintenance phases using fuzzy logic. The fuzzy approach is implemented to measure the impact of RCM technical indicators on sustainability. A broader recommendation to improve sustainable RCM is presented through an academic survey.
\end{abstract}

Keywords: Industry 5.0; Industry 4.0; Sustainability; Reliability Centered Maintenance; Fuzzy logic; High-value manufacturing

\section{Introduction}

The fifth industrial revolution, known as Industry 5.0 (I-5.0), has a vision for an innovative, resilient, socio-centred and competitive industry that minimises the negative environmental and social impacts and respects people, the planet and prosperity [1]. Six main technologies are identified to enable I-5.0 vision: (i) human-machine-interactive technologies; (ii) smart materials and bio-inspired technologies; (iii) Digital twins and real-time simulations; (iv) energy-efficient data transmission, storage, and analysis technologies; (v) Artificial Intelligence; and (vi) energy-efficient and renewables technologies for storage and autonomy [2]. I-5.0 has a different perspective on industry and technology in a way that you should ask yourself how new technologies can assist me rather than what I can do with this new technology? What be natural resources retrieved by new technology rather than consumed? What prosperity can be made to society? What value can be created for stakeholders rather than for shareholders?

According to European Commission experts' reports, the I-5.0 vision for industry transition should include the following three drivers: 'green transition', 'digital transition', and 'competitive transition'. Green transition aims to avoid climate change and environmental degradation. This requires amendments to the current economic growth strategies with a view to evade the net emission of greenhouse gases, disengaged resource use from economic growth, and support people and places around different regions and sectors.
European Commission proposed the key elements for fulfilling green transition as (1) supplying clean, affordable, secure energy, (2) mobilizing industry for a clean and circular economy, (3) promoting energy and resource efficiency, (4) accelerating the shift to sustainable and smart mobility, (5) providing a fair, healthy and environmentally friendly food system, (6) preserving and restoring ecosystem and biodiversity, (7) promoting zero pollution ambition, and (8) climate ambition for 2030 and 2050. Digital transition aims to support the circular economy by renovating digital strategies in terms of digital skills, data, technologies, and infrastructures. Competitive transition aims to convert marketing policies, regulations, and standards to bring more prosperity to people and create more value for businesses. It focuses on fair, competitive, innovative, and flexible business and marketing rules [3].

Industry 4.0 (I-4.0) technologies such as Internet of things (IoT), automation and digitisation, cyberphysical systems (CPS), blockchain, additive manufacture, artificial intelligence (AI), robotics, drones, virtual reality (VR) and augmented reality (AR) can support the I-5.0 vision by providing human-centric solutions and promoting the humanmachine integrated strength. For instance, smart materials with recyclability features, smart factories with energy-efficient automation technologies support I-5.0.

Bruntland describes sustainable development in 1987 as "development that meets the needs of the present without compromising the ability of future generations to meet their own needs [4]." The notion of 'triple bottom line' (economic, social, 
environmental) or 3 P's (profit, people, planet) is defined by Elkington in 1998 as the integrated sustainability pillars [5]. Future, high-value manufacturing should maintain sustainability and I5.0 goals. A report published in July 2020 by "Manufacturing Technology Association" has estimated that around 20 billion GBP will be added to the UK manufacturing industry by sustainable manufacturing, creating around a million jobs every year [6]. Businesses across the globe, now see the sustainability requirement not as an option, but as a necessity.

Through-life Engineering Services (TES) can be described as an integrated and seamless service strategy to support products throughout their lifecycle, focusing on optimising products' availability and reliability. Reliability centred maintenance (RCM) is a method for maintenance planning that was initially developed by the aerospace industry and later adapted to several highvalue manufacturing sectors [7]. Maintenance planning is a critical stage of asset management. Sustainable asset management and TES aim to create value for manufacturers and customers when providing efficient and effective support for highvalue, long life-span assets. The economic pillar of sustainability relates to profitability, productivity, products and services efficiency, and optimal return on capital investments. The social pillar can be enhanced by focusing on the health and safety of the workforce, working conditions of the workforce, morale, and motivation at work. The environmental impact can be reduced by supplying clean energy for production and operation, reducing air, soil, water and noise pollution, circular economy, and handling hazardous material safety.

This paper conducts a literature review on Industry 5.0 to investigate the industry technological enablers for a sustainable RCM and find the correlation between the integrated sustainability indicators and the identified RCM components.

\section{Literature review}

Back in 2016, at the time of Industry 4.0, the Japanese cabinet initiated the 5th Science and Technology Basic Plan called Society 5.0 [8]. There is no doubt that Society 5.0 goals have overlaps with I-5.0 targets to promote human resources and knowledge to overcome chronic economic and social challenges. Potočan et al. [9] investigated how Society 5.0 stabilities I-4.0 regarding economic development. Their study suggested the integration of advanced technologies in completing social goals and resolving social challenges. Welfare et al. [10] study shows that cobots can assist humans at the workplace by completing tasks that are more susceptible to health and safety risks, repetitive, long-hours, and feeling rushed. One of the I-5.0 challenges will be to design hybrid workplaces to implement and promote ethics in a human-machine co-working environment. Demir et al. [11] discussed the possible I-5.0 challenges regarding a collaborative human-robot co-working environment from the organizational and employment perspectives. Ethical issues, in particular, can be conversed in terms of career ambition, hardworking, dignity at work, and trustworthiness. Longo et al. [12] study focused on Factory of the Future. They specified the technological solutions that support human values, ethical related risks and issues emerging from I-5.0. Their research considered Schwartz's human values [13].

The concept of sustainable maintenance was recognised in the early $21^{\text {st }}$ century [14]. Sustainable maintenance studies initially focused on material and energy consumption. Garetti and Taisch [15] extend the work by Takata et al. [14] and studied the role of maintenance in asset lifecycle management. Nezami and Yildirim [16] study indicated that integration of sustainability and maintenance should not be limited to asset management activities and should influence the maintenance policies and strategies. Ighravwe and Oke [17] implement two different methodologies to rank maintenance sustainability in maintenance planning. The methods revealed two different results. Their research concluded that 'maintenance consumables optimization' and 'workforce training' are the best ranked sustainable maintenance strategies using fuzzy-TOPSIS and fuzzy axiomatic design principles.

Sustainable maintenance and its role in sustainable manufacturing have been studied extensively in the past. As a result, the literature identified many indicators for sustainable maintenance [15], [18]-[20]. A recent study identified integrated sustainability indicators in TES following a systematic review of the literature around sustainability assessment and TES [21]. The outcome of this research indicates the following top sustainability factors for operation and maintenance: servitization, customization, remaining sustainable life, predictive maintenance, real-time health monitoring, sustainable condition monitoring and remote maintenance. Following the literature review, the sustainability indicators, the relevant I5.0 enablers and the RCM components are identified as summarized in Table 1. 
Table 1. Sustainability indicators, Industry 5.0 enablers and reliability centred maintenance components

\begin{tabular}{|c|c|c|}
\hline $\begin{array}{l}\text { Sustainability } \\
\text { dimensions }\end{array}$ & Sustainable RCM key indicators & Industry 5.0 enablers \\
\hline Economic & $\begin{array}{l}\text { - Cost of maintenance (SR1) } \\
\text { - Revenue loss (SR 2) } \\
\text { - Ease of maintenance (SR 3) } \\
\text { - Predictive maintenance } \\
\text { - Continuous real-time monitoring }\end{array}$ & $\begin{array}{l}\text { - Automation technologies } \\
\text { - Virtual testing } \\
\text { - Smart dust } \\
\text { - Digital twin for maintenance }\end{array}$ \\
\hline Environmental & $\begin{array}{l}\text { - Pollution (SR 4) } \\
\text { - Resource/ energy consumption } \\
\text { (SR 5) } \\
\text { - 6R principles in service design } \\
\text { (SR 6) } \\
\text { - Renewable energy } \\
\end{array}$ & $\begin{array}{l}\text { - Supplying clean, affordable, secure } \\
\text { energy } \\
\text { - Smart/ recyclable/ lightweight materials } \\
\text { - Hydrogen and Power-to-X technologies } \\
\text { - Self-repairing and traceable material } \\
\text { - Biosensors and networked sensors }\end{array}$ \\
\hline Social & $\begin{array}{l}\text { - Working environment (SR 7) } \\
\text { - Workers health and safety (SR 8) } \\
\text { - Workers equality and diversity } \\
\text { - Training (SR 9) } \\
\text { - Regulatory compliance (SR 10) } \\
\text { - Dignity at work }\end{array}$ & - Human-AI interactive technologies \\
\hline $\begin{array}{l}\text { Economic- } \\
\text { Environmental }\end{array}$ & $\begin{array}{l}\text { - Circular economy } \\
\text { - Reverse logistics }\end{array}$ & $\begin{array}{l}\text { - Sustainable and smart mobility } \\
\text { - Energy-efficient smart factories }\end{array}$ \\
\hline $\begin{array}{l}\text { Social- } \\
\text { Economy }\end{array}$ & $\begin{array}{l}\text { - Servitization } \\
\text { - PSS customization } \\
\text { - Remote maintenance }\end{array}$ & $\begin{array}{l}\text { - AR } \\
\text { - VR and } \\
\text { - mix-reality for training }\end{array}$ \\
\hline $\begin{array}{l}\text { Social- } \\
\text { Environment }\end{array}$ & $\begin{array}{l}\text { - Sustainable resource planning } \\
\text { - Lean principles }\end{array}$ & - Human assistance cobots \\
\hline
\end{tabular}

\begin{tabular}{l}
\hline $\begin{array}{l}\text { RCM components and } \\
\text { indicators }\end{array}$ \\
\hline R1: Measurement and NDT \\
techniques \\
\hline $\begin{array}{l}\text { R2: Accuracy of monitored } \\
\text { parameters }\end{array}$ \\
\hline $\begin{array}{l}\text { R3: Feasibility of condition } \\
\text { monitoring }\end{array}$ \\
\hline R4: Operating conditions for \\
health monitoring \\
\hline R5: Monitoring interval \\
\hline R6: Data acquisition rate \\
\hline $\begin{array}{l}\text { R7: Fault detections and } \\
\text { sensors location }\end{array}$ \\
\hline $\begin{array}{l}\text { R8: Measurement and } \\
\text { trending }\end{array}$ \\
\hline R9: Quality of measurement \\
\hline $\begin{array}{l}\text { R10: Diagnosis and } \\
\text { prognosis }\end{array}$
\end{tabular}

\section{Methodology}

In this study, the research design includes qualitative, quantitative and mixed approaches. The research methodology comprises five main stages: problem definition, data collection, data analysis, validation, and conclusion. Step 1: problem definition: This study investigates Industry 5.0 indicators required to achieve sustainable RCM for high-value equipment. Moreover, this paper examines the feasibility of a correlation between sustainable indicators between operation and maintenance. Step 2: Data collection: the primary data collection is carried out by sending a questionnaire and an online survey to 15 academic members at the University and 4 industrial experts. Complete responses were only received from 7 academics and 3 industrial experts due to the Covid19 restrictions. The secondary data are collected through reviewing the relevant literature in 'sustainable maintenance', 'RCM' and 'Industry 5.0 '. Key indicators of the sustainable industrial revolution through I-5.0 in the context of high-value equipment operation and maintenance are identified. Moreover, the main components of the operation and maintenance for RCM are specified.

Step 3: Data analysis: an online survey focused on RCM components was sent to 10 experts. After collecting data, a Fuzzy TOPSIS approach was applied to collected data to get the impact ranking to assess the impact level of various indicators on sustainability (SR1-SR10). Step 4: Data validation: benchmarking is completed to compare the research results with existing knowledge from literature. Step 5: Conclusion: the concluding remarks are drawn to identify the area that I-5.0 can enable sustainable RCM most.

\section{Results}

In this study, based on the survey results, 10 sustainability indicators and 10 RCM components are considered and ranked using the Fuzzy TOPSIS method. Each expert is assigned equal importance with the weight of $(0.1,0.1,0.1)$. A triangular membership function of lower (L), middle (M), upper $(\mathrm{U})$ values are used for the calculation of fuzzy (see Appendix A1). First, the economic indicator 'cost of maintenance' has been selected, and the analysis is detailed in this Section.

Step-1: The evaluation matrix is therefore created based on the Experts (E) responses for each RCM component, matrix $\left(x_{i j}\right)_{10 \times 10}$, where, $x_{i j}=\left(l_{i j}, m_{i j}, u_{i j}\right)$.

Step-2: To calculate the impact level through Fuzzy TOPSIS, the positive and negative ideal solutions as maximum $\left(r_{i j}^{*}\right)$ and minimum $\left(r_{i j}^{-}\right)$impact solutions are considered. the normalised matrix is created using Equation (1) and (2):

$$
\begin{aligned}
& r_{i j}^{*}=\left(\frac{l_{i j}}{u_{j}^{*}}, \frac{m_{i j}}{u_{j}^{*}}, \frac{u_{i j}}{u_{j}^{*}}\right), \text { where: } u_{j}^{*}=\max _{i} u_{i j} \\
& r_{i j}^{-\bar{c}}=\left(\frac{l_{j}^{-}}{u_{i j}}, \frac{l_{j}^{-}}{u_{i j}}, \frac{l_{j}}{l_{i j}}\right) \text {, where } l_{j}^{-}=\min _{i} l_{i j}
\end{aligned}
$$

Step-3: The weighted normalised decision matrix $\left(\tilde{v}_{i j}\right)$, is calculated as follows, where, $\left(\widetilde{w}_{i j}\right)$ is the weight vector:

$$
\tilde{v}_{i j}=\left(\tilde{r}_{i j} \cdot \widetilde{w}_{i j}\right)_{10 \times 10}
$$

Following Steps 1-3, the decision matrix for RCM components is created as in Table 2 . 
Table 2. Weighted normalised decision matrix

\begin{tabular}{|c|c|c|c|c|c|c|c|c|c|c|}
\hline$\tilde{v}_{i j}$ & E1 & E2 & E3 & E4 & E5 & E6 & E7 & E8 & E9 & E10 \\
\hline \multirow{2}{*}{$\begin{array}{l}\mathrm{R} \\
1\end{array}$} & $(0.056,0.05$ & $(0.033,0.03$ & $(0.033,0.04$ & $(0.056,0.05$ & $(0.033,0.03$ & $(0.033,0.03$ & $(0.033,0.04$ & $(0.033,0.03$ & $(0.033,0.04$ & $(0.033,0.04$ \\
\hline & $6,0.071)$ & $3,0.043)$ & $3,0.060)$ & $6,0.071)$ & $3,0.043)$ & $3,0.043)$ & $3,0.060)$ & $3,0.043)$ & $3,0.060)$ & $3,0.060)$ \\
\hline \multirow{2}{*}{$\begin{array}{l}\mathrm{R} \\
{ }_{2}\end{array}$} & $(0.056,0.05$ & $(0.033,0.03$ & $(0.033,0.03$ & $(0.056,0.05$ & $(0.043,0.06$ & $(0.033,0.04$ & $(0.033,0.03$ & $(0.033,0.04$ & $(0.033,0.03$ & $(0.033,0.04$ \\
\hline & $6,0.071)$ & $3,0.043)$ & $3,0.043)$ & $6,0.071)$ & $0,0.100)$ & $3,0.060)$ & $3,0.043)$ & $3,0.060)$ & $3,0.043)$ & $3,0.060)$ \\
\hline \multirow{2}{*}{$\begin{array}{l}\mathrm{R} \\
3\end{array}$} & $(0.056,0.07$ & $(0.033,0.04$ & $(0.033,0.04$ & $(0.056,0.07$ & $(0.033,0.04$ & $(0.043,0.06$ & $(0.033,0.04$ & $(0.043,0.06$ & $(0.033,0.04$ & $(0.043,0.06$ \\
\hline & $1,0.100)$ & $3,0.060)$ & $3,0.060)$ & $1,0.100)$ & $3,0.060)$ & $0,0.100)$ & $3,0.060)$ & $0,0.100)$ & $3,0.060)$ & $0,0.100)$ \\
\hline \multirow{2}{*}{$\begin{array}{l}\mathrm{R} \\
4\end{array}$} & $(0.056,0.07$ & $(0.033,0.03$ & $(0.043,0.06$ & $(0.056,0.07$ & $(0.033,0.03$ & $(0.033,0.03$ & $(0.043,0.06$ & $(0.043,0.06$ & $(0.043,0.06$ & $(0.033,0.03$ \\
\hline & $1,0.100)$ & $3,0.043)$ & $0,0.100)$ & $1,0.100)$ & $3,0.043)$ & $3,0.043)$ & $0,0.100)$ & $0,0.100)$ & $0,0.100)$ & $3,0.043)$ \\
\hline \multirow{2}{*}{$\begin{array}{l}\mathrm{R} \\
5\end{array}$} & $(0.056,0.05$ & $(0.033,0.04$ & $(0.043,0.06$ & $(0.056,0.07$ & $(0.033,0.04$ & $(0.033,0.03$ & $(0.033,0.03$ & $(0.043,0.06$ & $(0.033,0.03$ & $(0.033,0.03$ \\
\hline & $6,0.071)$ & $3,0.060)$ & $0,0.100)$ & $1,0.100)$ & $3,0.060)$ & $3,0.043)$ & $3,0.043)$ & $0,0.100)$ & $3,0.043)$ & $3,0.043)$ \\
\hline \multirow[t]{2}{*}{$\mathrm{R}$} & $(0.056,0.05$ & $(0.033,0.03$ & $(0.033,0.03$ & $(0.056,0.05$ & $(0.033,0.03$ & $(0.033,0.04$ & $(0.033,0.03$ & $(0.033,0.04$ & $(0.033,0.03$ & $(0.033,0.04$ \\
\hline & $6,0.071)$ & $3,0.043)$ & $3,0.043)$ & $6,0.071)$ & $3,0.043)$ & $3,0.060)$ & $3,0.043)$ & $3,0.060)$ & $3,0.043)$ & $3,0.060)$ \\
\hline \multirow[t]{2}{*}{$\mathrm{R}$} & $(0.056,0.07$ & $(0.033,0.04$ & $(0.033,0.04$ & $(0.056,0.07$ & $(0.033,0.04$ & $(0.043,0.06$ & $(0.033,0.04$ & $(0.033,0.04$ & $(0.033,0.04$ & $(0.033,0.03$ \\
\hline & $1,0.100)$ & $3,0.060)$ & $3,0.060)$ & $1,0.100)$ & $3,0.060)$ & $0,0.100)$ & $3,0.060)$ & $3,0.060)$ & $3,0.060)$ & $3,0.043)$ \\
\hline \multirow[t]{2}{*}{$\mathrm{R}$} & $(0.056,0.07$ & $(0.043,0.06$ & $(0.033,0.03$ & $(0.056,0.05$ & $(0.033,0.03$ & $(0.043,0.06$ & $(0.033,0.03$ & $(0.043,0.06$ & $(0.033,0.03$ & $(0.043,0.06$ \\
\hline & $1,0.100)$ & $0,0.100)$ & $3,0.043)$ & $6,0.071)$ & $3,0.043)$ & $0,0.100)$ & $3,0.043)$ & $0,0.100)$ & $3,0.043)$ & $0,0.100)$ \\
\hline \multirow[t]{2}{*}{ R } & $(0.056,0.05$ & $(0.033,0.03$ & $(0.033,0.03$ & $(0.056,0.05$ & $(0.033,0.03$ & $(0.033,0.04$ & $(0.033,0.03$ & $(0.043,0.06$ & $(0.033,0.03$ & $(0.033,0.03$ \\
\hline & $6,0.071)$ & $3,0.043)$ & $3,0.043)$ & $6,0.071)$ & $3,0.043)$ & $3,0.060)$ & $3,0.043)$ & $0,0.100)$ & $3,0.043)$ & $3,0.043)$ \\
\hline \multirow{2}{*}{$\begin{array}{l}\mathrm{R} \\
10\end{array}$} & $(0.056,0.05$ & $(0.033,0.03$ & $(0.033,0.04$ & $(0.056,0.05$ & $(0.033,0.03$ & $(0.033,0.03$ & $(0.033,0.03$ & $(0.033,0.04$ & $(0.033,0.03$ & $(0.033,0.03$ \\
\hline & $6,0.071)$ & $3,0.043)$ & $3,0.060)$ & $6,0.071)$ & $3,0.043)$ & $3,0.043)$ & $3,0.043)$ & $3,0.060)$ & $3,0.043)$ & $3,0.043)$ \\
\hline
\end{tabular}

Step-4: The maximum impact ideal $\left(A^{*}\right)$ and minimum impact ideal $\left(A^{-}\right)$of the alternatives can be defined respectively as shown in Equation (4) and Equation (5) as follows:

$$
\begin{aligned}
& A^{*}=\left\{\tilde{v}_{1}^{*}, \tilde{v}_{2}^{*}, \ldots, \tilde{v}_{n}^{*}\right\}=\left\{\left(\max _{j} v_{i j} \mid i \in B\right),\left(\min _{j} v_{i j} \mid i \in C\right)\right\} \\
& A^{-}=\left\{\tilde{v}_{1}^{-}, \tilde{v}_{2}^{-}, \ldots, \tilde{v}_{n}^{-}\right\}=\left\{\left(\min _{j} v_{i j} \mid i \in B\right),\left(\max _{j} v_{i j} \mid i \in C\right)\right\}
\end{aligned}
$$

where, $\tilde{v}_{i}^{*}$ is the max value of $i$ for all the alternatives and $\tilde{v}_{i}^{-}$is the min value of $i$ for all the alternatives. $\mathrm{B}$ and $\mathrm{C}$ represent the maximum and minimum ideal solutions, respectively. The resultant maximum and minimum impact solutions from Equation (4) and Equation (5) are shown in Table 3.

Table 3. Maximum and minimum impact solutions

\begin{tabular}{lcc}
\hline & $A^{*}$ & $A^{-}$ \\
\hline $\mathrm{R}_{1}$ & $(0.056,0.056,0.071)$ & $(0.056,0.071,0.100)$ \\
\hline $\mathrm{R}_{2}$ & $(0.033,0.033,0.043)$ & $(0.043,0.060,0.100)$ \\
\hline $\mathrm{R}_{3}$ & $(0.033,0.033,0.043)$ & $(0.043,0.060,0.100)$ \\
\hline $\mathrm{R}_{4}$ & $(0.056,0.056,0.071)$ & $(0.056,0.071,0.100)$ \\
\hline $\mathrm{R}_{5}$ & $(0.033,0.033,0.043)$ & $(0.043,0.060,0.100)$ \\
\hline $\mathrm{R}_{6}$ & $(0.033,0.033,0.043)$ & $(0.043,0.060,0.100)$ \\
\hline $\mathrm{R}_{7}$ & $(0.033,0.033,0.043)$ & $(0.043,0.060,0.100)$ \\
\hline $\mathrm{R}_{8}$ & $(0.033,0.033,0.043)$ & $(0.043,0.060,0.100)$ \\
\hline $\mathrm{R}_{9}$ & $(0.033,0.033,0.043)$ & $(0.043,0.060,0.100)$ \\
\hline $\mathrm{R}_{10}$ & $(0.033,0.033,0.043)$ & $(0.043,0.060,0.100)$ \\
\hline
\end{tabular}

Step-5: The distance between each alternative and fuzzy maximum impact ideal solution $S_{i}^{*}$ and the distance between each alternative and fuzzy minimum impact ideal solution $S_{i}^{-}$are respectively calculated using in Equation (6) and Equation (7):

$$
\begin{array}{ll}
S_{i}^{*}=\sum_{j=1}^{n} d\left(\tilde{v}_{i j}, \tilde{v}_{j}^{*}\right) & \mathrm{i}, \mathrm{j}=1,2, \ldots, 10 \\
S_{i}^{-}=\sum_{j=1}^{n} d\left(\tilde{v}_{i j}, \tilde{v}_{j}^{-}\right) & \mathrm{i}, \mathrm{j}=1,2, \ldots, 10
\end{array}
$$

where, $d\left(\tilde{v}_{i j}, \tilde{v}_{j}^{*}\right)$ and $d\left(\tilde{v}_{i j}, \tilde{v}_{j}^{-}\right)$are crisp numbers and $d$ is the distance between two fuzzy numbers when given two triangular fuzzy numbers $\left.l_{1}, m_{1}, u\right)$ and $\left(l_{2}, m_{2}, u\right)$, the distance between the two can be calculated as shown in Equation (8):

$$
d_{v}\left(\widetilde{M}_{1}, \widetilde{M}_{2}\right)=\sqrt{\frac{1}{3}\left[\left(l_{1}-l_{2}\right)^{2}+\left(m_{1}-m_{2}\right)^{2}+\left(u_{1}-u_{2}\right)^{2}\right]}
$$

\begin{tabular}{|c|c|c|c|c|c|c|c|c|c|c|}
\hline & $\begin{array}{l}\mathrm{R} \\
1\end{array}$ & $\begin{array}{l}\mathrm{R} \\
\mathrm{R}\end{array}$ & $\begin{array}{l}\mathrm{R} \\
3\end{array}$ & $\begin{array}{l}\mathrm{R} \\
4\end{array}$ & $\begin{array}{l}\mathrm{R} \\
5\end{array}$ & $\begin{array}{l}\mathrm{R} \\
{ }_{6}\end{array}$ & $\begin{array}{l}\mathrm{R} \\
7\end{array}$ & $\begin{array}{l}\mathrm{R} \\
8\end{array}$ & $\begin{array}{l}\mathrm{R} \\
{ }_{9}\end{array}$ & $\begin{array}{l}\mathrm{R} \\
10\end{array}$ \\
\hline$S_{i}^{*}$ & $\begin{array}{l}\stackrel{n}{Ð} \\
0\end{array}$ & $\underset{0}{\tilde{S}}$ & 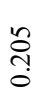 & $\frac{\mathscr{\infty}}{\dot{\infty}}$ & $\begin{array}{l}n \\
\Xi \\
0\end{array}$ & 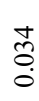 & $\frac{\stackrel{+}{ \pm}}{\stackrel{0}{0}}$ & $\begin{array}{l}0 \\
\stackrel{0}{0} \\
0\end{array}$ & $\underset{0}{\stackrel{\infty}{+}}$ & 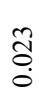 \\
\hline$S_{i}^{-}$ & 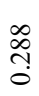 & $\begin{array}{l}\text { ָै } \\
\text { ஸ̣ }\end{array}$ & $\frac{\stackrel{\Im}{I}}{0}$ & $\frac{\tilde{f}}{\dot{\sigma}}$ & $\frac{\infty}{\sim}$ & ते & $\stackrel{\vec{\sigma}}{\overrightarrow{0}}$ & $\begin{array}{l}\mathscr{0} \\
\stackrel{0}{0}\end{array}$ & $\begin{array}{l}\stackrel{+}{\infty} \\
\text { ஸ̣ } \\
0\end{array}$ & $\frac{0}{\mathfrak{n}}$ \\
\hline
\end{tabular}

The results for distance from maximum and minimum impacts are presented in Table 4.

Step-6: The closeness coefficient of each alternative can be calculated as shown in Equation

$$
C_{i}=\frac{S_{i}^{-}}{S_{i}^{*}+S_{i}^{-}}
$$

The best alternative is closest to the fuzzy maximum impact ideal solution and farthest to the fuzzy minimum impact ideal solution. Assessment of impact level is repeated for each sustainability indicator (SR1 - SR10), based on the responses received from subject experts. The results of the decision matrix with the top 3 major components which impact sustainability indicators are presented in Table 5.

\section{Discussion}

The outcome of this study indicated the economic dimensions, 'cost of maintenance' and 'loss of revenue' are most influenced by 'diagnosis and prognosis'. The social dimensions 'workers health and safety' and 'physical environment' can be most influenced by 'operating condition during monitoring'. 'measurement and NDT techniques influence 'pollution', 'circular economy', and 'training' indicators of environmental sustainability. 
Table 5. Correlation matrix for impact level of each sustainability indicator

\begin{tabular}{cccccccccccc}
\hline \multicolumn{1}{c}{} & & $\mathrm{R} 1$ & $\mathrm{R} 2$ & $\mathrm{R} 3$ & $\mathrm{R} 4$ & $\mathrm{R} 5$ & $\mathrm{R} 6$ & $\mathrm{R} 7$ & $\mathrm{R} 8$ & $\mathrm{R} 9$ & $\mathrm{R} 10$ \\
\hline $\mathrm{SR} 1$ & $C_{i 1}$ & 0.864 & 0.787 & 0.386 & 0.443 & 0.654 & 0.898 & 0.573 & 0.5 & 0.855 & 0.932 \\
\hline & Rank & 3 & 5 & 10 & 9 & 6 & 2 & 7 & 8 & 4 & 1 \\
\hline SR2 & $C_{i 2}$ & 0.847 & 0.751 & 0.741 & 0.389 & 0.401 & 0.216 & 0.804 & 0.542 & 0.556 & 0.937 \\
\hline & Rank & 2 & 3 & 5 & 9 & 8 & 10 & 4 & 7 & 6 & 1 \\
\hline SR3 & $C_{i 3}$ & 0.601 & 0.454 & 0.833 & 0.577 & 0.623 & 0.622 & 0.601 & 0.66 & 0.615 & 0.8 \\
\hline & Rank & 7 & 9 & 1 & 8 & 4 & 5 & 7 & 3 & 6 & 2 \\
\hline SR4 & $C_{i 4}$ & 0.825 & 0.452 & 0.698 & 0.454 & 0.782 & 0.588 & 0.515 & 0.63 & 0.579 & 0.772 \\
\hline & Rank & 1 & 10 & 4 & 9 & 3 & 6 & 8 & 5 & 7 & 2 \\
\hline SR5 & $C_{i 5}$ & 0.698 & 0.462 & 0.373 & 0.551 & 0.282 & 0.28 & 0.845 & 0.551 & 0.53 & 0.623 \\
\hline & Rank & 2 & 6 & 7 & 4 & 8 & 9 & 1 & 4 & 5 & 3 \\
\hline SR6 & $C_{i 6}$ & 0.826 & 0.703 & 0.541 & 0.607 & 0.551 & 0.418 & 0.659 & 0.348 & 0.472 & 0.538 \\
\hline & Rank & 1 & 2 & 6 & 4 & 5 & 9 & 3 & 10 & 8 & 7 \\
\hline SR7 & $C_{i 7}$ & 0.639 & 0.371 & 0.686 & 0.796 & 0.433 & 0.433 & 0.363 & 0.43 & 0.42 & 0.588 \\
\hline & Rank & 3 & 8 & 2 & 1 & 5 & 5 & 9 & 6 & 7 & 4 \\
\hline SR8 & $C_{i 8}$ & 0.635 & 0.635 & 0.534 & 0.914 & 0.423 & 0.534 & 0.529 & 0.826 & 0.721 & 0.635 \\
\hline & Rank & 4 & 4 & 5 & 1 & 7 & 5 & 6 & 2 & 3 & 4 \\
\hline SR9 & $C_{i 9}$ & 0.874 & 0.672 & 0.308 & 0.465 & 0.81 & 0.385 & 0.39 & 0.468 & 0.612 & 0.597 \\
\hline & Rank & 1 & 3 & 10 & 7 & 2 & 9 & 8 & 6 & 4 & 5 \\
\hline SR10 & $C_{i 10}$ & 0.82 & 0.753 & 0.62 & 0.576 & 0.362 & 0.437 & 0.366 & 0.364 & 0.44 & 0.56 \\
\hline & Rank & 1 & 2 & 3 & 4 & 10 & 7 & 8 & 9 & 6 & 5 \\
\hline
\end{tabular}

Diagnosis and prognosis contribute to detecting a defect, prediction of remaining useful life (RUL). The process of prediction of health and estimation of RUL can influence economic performance in the form of, unavailability of equipment and poor quality of the product [22]. Regarding the environmental dimension, 'measurement techniques' has the most impact on sustainability. Measurement techniques directly affect usage of resources, level of pollution and scope of reusability. Measurement techniques also directly relate to the accuracy and durability of the maintenance procedure [23]. The social dimension of sustainability is mainly affected by 'operating condition during monitoring'. Similar results were obtained by [24]. They found lighting and ventilation and occupational health and safety are influenced sustainability most. Hendiani et al. [25] and Sari e al. [26] also realised the importance of operating conditions for social sustainability in the construction industry and stated that health and safety practices and regulations, and prohibition are few key important factors for social sustainability.

\section{Concluding remarks}

The project offers a quantitative relationship between sustainability indicators and components of the operation and maintenance phase of reliability centered maintenance. Following the survey results from 10 experts, 10 sustainability indicators across economic, environmental and social dimensions are selected. The top then RCM components are also identified from the literature and the survey results. The Fuzzy TOPSIS with a triangular membership function is implemented to identify the correlation between sustainability indicators and the RCM components.
Diagnosis and prognosis are most influential for economic sustainability, measurement techniques for environmental sustainability and operating conditions during maintenance for social sustainability of RCM. This research highlighted that a quantitative correlation is feasible between RCM components and integrated sustainability indicators, which can help industry professionals and planners to identify and implement sustainable maintenance strategies. Overall, the results indicated that the RCM components 'Data acquisition rate' and 'measurement and sensor locations' have the most impact on sustainability. Availability, accessibility and agility in data transient and just-intime data capturing is crucial for sustainability. Moreover, measurements' type and location for fault detection, accessibility of sensors, and signal conditioning are crucial for sustainability.

Industry 5.0 mission is to ensure technologies and innovations support humanity. Following the recent Covid-19 pandemic experience, I-5.0 is needed to focus on industry and technology resilience and sustainability. The global economic crisis shows that industry, innovation, and technology are still vulnerable. It is expected that I-5.0 solutions improve the resilience and robustness of industries and technologies to resolve this weakness.

Although it is challenging to quantify the environmental and social impacts of RCM activities, this study shows the feasibility of a strong correlation between sustainable indicators and RCM components. Technologies and workplaces must provide safety, security and integrity. Identifying skill gaps and providing several training sessions is necessary for businesses when adopting new technology and creating a machine-human integrated workplace. 
Further research should focus on exploring technological solutions and practical roadmap industries to promote integrated sustainability in the context of I-5.0, focusing on social-economic and social-environmental dimensions.

\section{Acknowledgements}

This research is supported by the Centre for Digital Engineering and Manufacturing (CDEM) at Cranfield University.

\section{Appendix A.}

\section{Fuzzy scales for the membership function}

\begin{tabular}{lllll}
\hline Code & Linguistic term & $(\mathrm{L})$ & $(\mathrm{M})$ & $(\mathrm{U})$ \\
\hline 1 & Very low & 1 & 1 & 3 \\
\hline 2 & Low & 1 & 3 & 5 \\
\hline 3 & Medium & 3 & 5 & 7 \\
\hline 4 & High & 5 & 7 & 9 \\
\hline 5 & Very high & 7 & 9 & 9 \\
\hline
\end{tabular}

\section{References}

[1] Müller J. Enabling Technologies for Industry 5.0 - Results of a workshop with Europe's technology leaders 2020. doi: $10.2777 / 082634$.

[2] De Nul L, Breque M, Petridis A. Industry 5.0 - Towards a sustainable, human-centric and resilient European industry. 2021. doi:10.2777/308407.

[3] Breque M, Nul L De, Petridis A. Industry 5.0 Towards a sustainable, humancentric and resilient European industry. Brussels: 2021.

[4] Brundtland GH. Report of the World Commission on Environment and Development Our Common Future. Oslo, Norway: 1987. doi:10.9774/gleaf.978-1-907643-44-6_12.

[5] Elkington J. Partnerships from cannibals with forks: The triple bottom line of 21 st-century business. Environ Qual Manag 1998;8:37-51. doi:10.1002/tqem.3310080106.

[6] Williamson J. Sustainable manufacturing could boost UK GDP by $£ 20$ bn and create 1 million jobs. Manuf 2020 . https://www.themanufacturer.com/articles/sustainablemanufacturing-boost-uk-gdp-20bn-create-1-million-jobs/ (accessed June 16, 2021)

[7] Raus M, Vatn J. Reliability Centred Maintenance. Springer Ser. Reliab. Eng., vol. 8, Springer London; 2008, p. 79-108. doi:10.1007/978-1-84800-011-7_4.

[8] Cabinet Office "Government of Japan." [Tentative Translation] Report on The 5 th Science and Technology Basic Plan. 2015

[9] Potočan V, Mulej M, Nedelko Z. Society 5.0: balancing of Industry 4.0, economic advancement and social problems. Kybernetes 2020;50:794-811. doi:10.1108/K-12-20190858 .

[10] Welfare KS, Hallowell MR, Shah JA, Riek LD. Consider the Human Work Experience When Integrating Robotics in the Workplace. ACM/IEEE Int Conf Human-Robot Interact
2019;2019-March:75-84 doi:10.1109/HRI.2019.8673139.

[11] Demir KA, Döven G, Sezen B. Industry 5.0 and HumanRobot Co-working. Procedia Comput Sci 2019;158:68895. doi:10.1016/j.procs.2019.09.104.

[12] Longo F, Padovano A, Umbrello S. Value-oriented and ethical technology engineering in industry 5.0: A humancentric perspective for the design of the factory of the future. Appl Sci 2020;10:1-25. doi:10.3390/APP10124182.

[13] Schwartz SH, Bilsky W. Toward A Universal Psychological Structure of Human Values. J Pers Soc Psychol 1987;53:550-62. doi:10.1037/0022-3514.53.3.550.

[14] Takata S, Kimura F, Van Houten FJAM, Westkämper E, Shpitalni M, Ceglarek D, et al. Maintenance: Changing role in life cycle management. CIRP Ann - Manuf Technol 2004;53:643-55. doi:10.1016/S0007-8506(07)60033-X.

[15] Garetti M, Taisch M. Sustainable manufacturing: Trends and research challenges. Prod Plan Control 2012;23:83104. doi:10.1080/09537287.2011.591619.

[16] Nezami FG, Yildirim MB. A sustainability approach for selecting maintenance strategy. Int $J$ Sustain Eng 2013;6:332-43. doi:10.1080/19397038.2013.765928.

[17] Ighravwe DE, Oke SA. Ranking maintenance strategies for sustainable maintenance plan in manufacturing systems using fuzzy axiomatic design principle and fuzzy-TOPSIS. J Manuf Technol Manag 2017;28:961-92. doi:10.1108/JMTM-01-2017-0007.

[18] Franciosi C, Voisin A, Miranda S, Riemma S, Iung B. Measuring maintenance impacts on sustainability of manufacturing industries: from a systematic literature review to a framework proposal. J Clean Prod 2020;260:121065. doi:10.1016/j.jclepro.2020.121065.

[19] Parida A, Kumar U, Galar D, Stenström C. Performance measurement and management for maintenance: A literature review. J Qual Maint Eng 2015;21:2-33. doi:10.1108/JQME-10-2013-0067.

[20] Hristov I, Chirico A. The role of sustainability key performance indicators (KPIs) in implementing sustainable strategies. Sustain 2019;11:5742. doi:10.3390/su11205742.

[21] Farsi M, Erkoyuncu JA. Toward an Integrated Sustainability Assessment in Through-life Engineering Services. 9th Int. Conf. Through-life Eng. Serv., Cranfield: SSRN; 2020. doi:10.2139/ssrn.3718041.

[22] Baur M, Albertelli P, and Monno, M. A review of prognostics and health management of machine tools. The International Journal of Advanced Manufacturing Technology 2020;107(5), pp.2843-2863.

[23] Jiang A, Dong N, Tam KL, and Lyu C. Development and optimization of a condition-based maintenance policy with sustainability requirements for production system. Mathematical Problems in Engineering, 2018.

[24] Amrina E, Yulianto A, and Kamil I. Fuzzy multi criteria approach for sustainable maintenance evaluation in rubber industry. Procedia Manufacturing 2019;33, pp.538-545.

[25] Hendiani S, Liao H, Bagherpour M, Tvaronavičienè M, Banaitis A, and Antucheviciene J. Analyzing the status of sustainable development in the manufacturing sector using multi-expert multi-criteria fuzzy decision-making and integrated triple bottom lines. International journal of environmental research and public health 2020;17(11), p.3800.

[26] Sari E, Shaharoun AM, Ma'aram A, and Yazid AM. Sustainable maintenance performance measures: a pilot survey in Malaysian automotive companies. Procedia CIRP 2015;26, pp.443-448. 
2021-10-19

\title{
Industry 5.0 for sustainable reliability centered maintenance
}

\author{
Farsi, Maryam
}

Elsevier

Farsi M, Mishra RK, Erkoyuncu JA. (2021) Industry 5.0 for sustainable reliability centered maintenance. In: 10th International Conference on Through-life Engineering Services (TESConf 2021), 16-17 November 2021, Virtual Event: Host: University of Twente https://doi.org/10.2139/ssrn.3944533

Downloaded from Cranfield Library Services E-Repository 